\title{
O CABO, O CAPITÃO E O CAPITAL ${ }^{1}$ \\ EL CABO, EL CAPITÁN Y LA CAPITAL \\ THE CAPE, THE CAPTAIN AND THE CAPITAL
}

Aluizio ALVES FILHO²

Doutor em História pela Universidade de São Paulo e professor da Universidade Federal do Rio de Janeiro com longa experiência profissional dedicada ao ensino e à pesquisa, o professor Lincoln de Abreu Penna vem brindando o público estudioso com ensaios que primam pela relevância e originalidade, entre os quais está a recente publicação do livro " $O$ cabo, o capitão e o capital - um exercício de história comparada". Nesta obra o autor examina algumas coincidências entre as trajetórias políticas de Adolf Hitler e de Jair Messias Bolsonaro. Isto de maneira alguma quer dizer que considere o procedimento político do segundo redutível ao do primeiro, que é responsável por crime de genocídio só comparável àquele de que os negros africanos foram vítimas durante os séculos em que foram trazidos como escravos do seu rincão natal para terras do novo mundo.

O ponto central de que o autor se vale para inicialmente aproximar e estabelecer parâmetros que possibilitam a comparação entre o político alemão e o brasileiro é o de que, apesar de as ações de ambos terem se dado em momentos históricos cronologicamente bastante distanciados, ambas se iniciaram em ocasiões nas quais havia fortes crises no capitalismo.

Outro ponto em comum apontado por Lincoln é o fato de o procedimento dos dois ter em comum uma radical intolerância por seus opositores, que consideram e tratam como inimigos, e não adversários em pleitos democráticos. Hitler e Bolsonaro podem, portanto, ser entendidos como "personalidades autoritárias", segundo conceito construído pelo sociólogo Alemão Theodor Adorno em estudo clássico de quase mil páginas publicado originalmente nos Estados Unidos, em 1950 ("The authoritatarian personality”). Entre as características mais marcantes da personalidade autoritária estão a intolerância, o egocentrismo, a

${ }^{1}$ Resenha do livro de Lincoln de Abreu Penna. O Cabo, o Capitão e o Capital. Rio de Janeiro: Letra Capital, 2020.

${ }^{2}$ Universidade Federal do Rio de Janeiro (UFRJ), Rio de Janeiro - RJ - Brasil. Professor Aposentado do Departamento de Ciências Sociais. Doutorado em Sociologia (UNB). ORCID: https://orcid.org/0000-0001-9510298X. E-mail: aluizio.alves@uol.com.br 
agressividade, o pensamento simplório, a indiferença pela necessidade dos que se opõem às suas lideranças, o narcisismo e uma desenfreada sede de poder.

A crise do capitalismo na Alemanha, que propiciou a então inesperada ascensão de Hitler ao poder, está diretamente ligada à derrota do país na primeira guerra mundial, seguida de uma paz humilhante que lhe foi imposta pelo tratado de Versalhes (1919) e pela grande depressão de 1929. Esta levou a já combalida economia alemã, condenada a pagar pesadas indenizações no pós-guerra, a viver uma espiral inflacionária que a conduziu à bancarrota, provocando grande índice de desemprego e descontentamentos generalizados. Foram estas as circunstâncias que possibilitaram ao cabo da Boemia, figura de proa do Partido Nazista - um partido inexpressivo quanto a apoio popular em seus primeiros anos de existência - a ver sua agremiação, prometendo reconstrução nacional, agigantar-se nas eleições de 1930 e 1932 e tornando-se de partido inexpressivo a uma força política no país. Fato que, no ano de 1933, levou o conservador, nacionalista e antiliberal presidente da república, Paul Von Hindenburg, a nomear Hitler chanceler. Com o falecimento de Hindenburg no ano seguinte, Hitler tornouse Fuhrer (líder), presidente e chanceler ao mesmo tempo. Contando com forte apoio entre militares e civis, adquiriu poder absoluto no país.

No Brasil, a ocorrência da crise do capitalismo, que abriria espaço para a também inesperada chegada de Bolsonaro à presidência da república em 2019, principia com a derrocada do Partido dos Trabalhadores (PT). Tal se deu em 2016, após 14 anos consecutivos no poder através de dois mandatos presidenciais de Lula e de um mandato e meio de Dilma Rousseff - que o sucedera e sofreu impeachment, acusada de pedaladas fiscais. Concretamente, a derrocada do PT foi devida a um complexo conjunto de fatores políticos e econômicos de natureza interna e externa que incluem erros da administração petista no combate à inflação, corrupção e o uso e abuso de farto material parcial e tendencioso publicado pela grande imprensa, ponta-de-lança dos interesses das classes dominantes. Tal campanha incentivou a derrubada dos governos petistas e sua substituição por um governo comprometido com medidas econômicas do chamado neoliberalismo, que, uma vez no poder, iniciou o desmonte do estado nacional por meio da venda, a preços aviltantes, de lucrativas empresas públicas. Governo que também retirou direitos historicamente conquistados a duras penas pelos trabalhadores, tanto do serviço público quanto do setor privado.

Além dos fatores acima citados, também contribuíram de forma decisiva para a chegada de Bolsonaro à presidência da república o desgaste junto à opinião pública sofrido pelo PT devido ao uso e abuso de fake news na campanha publicitária bolsonarista, além da frenética perseguição movida contra Lula pela Lava Jato, como ficou conhecida a força-tarefa 
curitibana que investigou irregularidades cometidas na Petrobras durante governos petistas. Investigações que culminaram com a condenação e prisão do ex-presidente, o que lhe tirou o direito de disputar a presidência da república no pleito eleitoral realizado em 2018, as pesquisas de opinião anteriores a sua prisão apontasse sua liderança na disputa.

Vale lembrar que, em decisão ainda recente, o Superior Tribunal Federal (STF) não só anulou as condenações de Lula - voltando seus processos à estaca zero - como também considerou que o ex-juiz e ex-ministro da justiça, Sergio Mouro, não agiu com a lisura e a independência que tipificam a magistratura.

A prisão de Lula e o desgaste vivido pelo PT evidenciados nos fatores até aqui elencados provocaram um vazio no poder que abriu caminho para a eleição de Bolsonaro. Associa-se ao dito a enigmática facada em Bolsonaro por ocasião de comício que realizava na cidade mineira de Juiz de Fora pouco antes das eleições. Facada real ou não que, criando comoção popular e mexendo emotivamente nas formas de pensar, sentir e agir da população, também foi fator basilar para a sua eleição, pois sem dúvida lhe rendeu milhares votos de eleitores até então indecisos ou que simplesmente ficaram comovidos, migrando de Haddad para o militar precocemente reformado.

Outros pontos em que o professor Lincoln coloca em evidência em sua análise comparativa são a origem profissional comum, ou seja, castrense, do político alemão e do brasileiro, assim como sérios problemas que então com a justiça ambos tiveram. Os dois responderam a processos disciplinares e, embora inicialmente dados como culpados, acabaram inocentados.

Hitler serviu ao exército alemão durante a primeira guerra mundial. Ingressou como soldado e pouco depois foi promovido a cabo. Em 1923 encabeçou uma tentativa de golpe de estado ao fomentar forte arruaça numa cervejaria em Munique, onde se encontrava acompanhado por militantes, como ele, partidários do nazismo. Foi preso, acusado de alta traição pela tentativa de subversão da ordem constitucional e, por tal razão, permaneceu preso por cerca de um ano, até ser julgado. A defesa, que durou horas, foi feita pelo próprio réu, um exímio orador que, em linguagem emotiva, assegurou que o ato que o levara à prisão fora feito por amor à pátria e na defesa de um povo humilhado e empobrecido pela situação desesperadora em que se encontrava a Alemanha no pós-guerra. O promotor pediu oito anos de prisão para Hitler, mas o juiz condenou-a a cinco, com livramento condicional em seis meses, e assim ocorreu.

Quanto a Bolsonaro, informa o professor Lincoln, em seu trabalho historiográfico, que em 1986, quando o militar era capitão da ativa no exército brasileiro, publicou na Revista 
Veja, na seção Ponto de Vista, um pequeno artigo intitulado "O salário está baixo", onde deixava clara sua insatisfação com o soldo que recebia. É evidente que tal manifestação atentava contra os princípios disciplinares que fazem do exército instituição altamente respeitada e admirada pelos brasileiros. A grave transgressão disciplinar do capitão não poderia passar nem passou em bancas nuvens pelos seus superiores hierárquicos. Os três coronéis que o julgaram por unanimidade propuseram que fosse expulso das gloriosas fileiras do exército pátrio. Bolsonaro recorreu da decisão ao Superior Tribunal Militar (STM) e, como Hitler, fez a sua própria defesa, obtendo parecer que não apenas lhe livrava da humilhante expulsão, como lhe preservava o soldo desde que solicitasse imediata passagem para a reserva, e assim o fez. Começava ali a carreira de Bolsonaro como político profíssional. Nesta, primeiro foi eleito vereador no Rio de Janeiro e, depois, seguidamente durante duas décadas, deputado Federal e finalmente presidente da república. No parlamento, sempre se colocou como representante dos interesses dos militares e se apresentou como patriota, ferrenho anticomunista, defensor de ditaduras, de torturadores e inteiramente avesso aos direitos humanos. Em linhas gerais, esse perfil parlamentar de Bolsonaro não mudou quando chegou à presidência da república, onde fez das forças armadas o coração do seu dito patriotismo, relegando a população civil, mormente os servidores públicos, e os pobres em geral, à posição de absoluto segundo plano.

Após os capítulos iniciais, onde o autor reporta e comenta aspectos centrais da trajetória de Hitler e de Bolsonaro desde os tempos da caserna até chegarem a ocupar o cargo máximo do poder executivo em seus respectivos países - o primeiro como ditador e o segundo, como presidente - fatos que se deram em momentos históricos diferenciados, mas tendo em comum a existência de forte crise econômica, política e social, nos capítulos que se seguem o autor volta seu olhar de historiador para a recepção de Hitler dentro e fora da Alemanha, buscando analisar de que maneira os ideais fascistas e antidemocráticas de procedência internacional repercutiram no Brasil, fazendo-se presente até os dias em curso.

Enfim, o livro resenhado é uma publicação oportuna e escrita no calor da hora, voltado não apenas para público acadêmico, mas para todos os verdadeiros patriotas preocupados com o futuro do nosso povo e com o papel positivo e impoluto que o Brasil deve desempenhar no concerto das nações.

\section{REFERÊNCIA}

PENNA, L. A. O cabo, o capitão e o capital. Rio de Janeiro: Letra Capital, 2020. 


\section{Como referenciar este artigo}

ALVES FILHO, A. O Cabo, o Capitão e o Capital. Rev. Sem Aspas, Araraquara, v. 10, e021007, jan./dez. 2021. e-ISSN: 2358-4238. DOI: https://doi.org/10.29373/sas.v10i00.15345

Submetido em: 02/05/2021

Aprovado em: 20/05/2021

Publicado em: 30/06/2021 